\title{
Purinergic responses of calcium-dependent signaling pathways in cultured adult human astrocytes
}

Sadayuki Hashioka ${ }^{1,4^{*}}$, Yun Fan Wang ${ }^{2}$, Jonathan P Little ${ }^{3}$, Hyun B Choi ${ }^{2}$, Andis Klegeris ${ }^{3}$, Patrick L McGeer ${ }^{1}$ and James G McLarnon ${ }^{2^{*}}$

\begin{abstract}
Background: The properties of $\mathrm{Ca}^{2+}$ signaling mediated by purinergic receptors are intrinsically linked with functional activity of astrocytes. At present little is known concerning $\mathrm{Ca}^{2+}$-dependent purinergic responses in adult human astrocytes. This work has examined effects of purinergic stimulation to alter levels of intracellular $\mathrm{Ca}^{2+}$ in adult human astrocytes. $\mathrm{Ca}^{2+}$-sensitive spectrofluorometry was carried out to determine mobilization of intracellular $\mathrm{Ca}^{2+}$ following adenosine triphosphate (ATP) or 3'-O-(4-benzoyl)benzoyl-ATP (Bz-ATP) stimulation of adult human astrocytes. In some experiments pharmacological modulation of $\mathrm{Ca}^{2+}$ pathways was applied to help elucidate mechanisms of $\mathrm{Ca}^{2+}$ signaling. RT-PCR was also performed to confirm human astrocyte expression of specific purinoceptors which were indicated from imaging studies.

Results: The endogenous P2 receptor agonist ATP (at $100 \mu \mathrm{M}$ or $1 \mathrm{mM}$ ) applied in physiological saline solution (PSS) evoked a rapid increase of $\left[\mathrm{Ca}^{2+}\right]_{i}$ to a peak amplitude with the decay phase of response exhibiting two components. The two phases of decay consisted of an initial rapid component which was followed by a secondary slower component. In the presence of $\mathrm{Ca}^{2+}$-free solution, the secondary phase of decay was absent indicating this prolonged component was due to influx of $\mathrm{Ca}^{2+}$. This prolonged phase of decay was also attenuated with the store-operated channel (SOC) inhibitor gadolinium (at $2 \mu \mathrm{M}$ ) added to standard PSS, suggesting this component was mediated by SOC activation. These results are consistent with ATP activation of P2Y receptor (P2YR) in adult human astrocytes leading to respective rapid $\left[\mathrm{Ca}^{2+}\right]_{\mathrm{i}}$ mobilization from intracellular stores followed by $\mathrm{Ca}^{2+}$ entry through SOC. An agonist for P2X7 receptor (P2X7R), BZATP induced a very different response compared with ATP whereby BzATP (at $300 \mu \mathrm{M}$ ) elicited a slowly rising increase in $\left[\mathrm{Ca}^{2+}\right]_{i}$ to a plateau level which was sustained in duration. The BzATP-induced increase in $\left[\mathrm{Ca}^{2+}\right]_{i}$ was not enhanced with lipopolysaccharide pre-treatment of cells as previously found for P2X7R mediated response in human microglia. RT-PCR analysis showed that adult human astrocytes in vitro constitutively express mRNA for P2Y1R, P2Y2R and P2X7R.
\end{abstract}

Conclusion: These results suggest that activation of metabotropic P2YR (P2Y1R and/or P2Y2R) and ionotropic P2X7R could mediate purinergic responses in adult human astrocytes.

Keywords: Adult human astrocytes, P2 receptors, Intracellular calcium signaling, ATP, 3'-O-(4-benzoyl)benzoyl-ATP

\footnotetext{
*Correspondence: hashioka@f2.dion.ne.jp; mclarnon@mail.ubc.ca

${ }^{1}$ Kinsmen Laboratory of Neurological Research, Department of Psychiatry,

The University of British Columbia, Vancouver, BC, Canada

${ }^{2}$ Department of Anesthesiology, Pharmacology and Therapeutics, The

University of British Columbia, 2176 Health Sciences Mall, Vancouver, BC V6T

1Z3, Canada

Full list of author information is available at the end of the article
} 


\section{Background}

Astrocytes respond to a variety of physiological and pathological stimuli with an increase in intracellular $\mathrm{Ca}^{2+}$ concentration $\left(\left[\mathrm{Ca}^{2+}\right]_{\mathrm{i}}\right)$, often referred to as " $\mathrm{Ca}^{2+}$ signaling" or " $\mathrm{Ca}^{2+}$ excitability" [1,2]. Astrocyte functional processes are intricately linked to, and shaped by, activation of particular purinergic receptors. Adenosine triphosphate (ATP) is one of the primary extracellular signaling molecules for astrocytes under both physiological and pathological conditions and evokes an astrocytic $\left[\mathrm{Ca}^{2+}\right]_{\mathrm{i}}$ elevation through activation of P2 purinoceptors [1]. P2 purinoceptors are subdivided into two families consisting of metabotropic P2Y receptor (P2YR) and ionotropic P2X receptor (P2XR). In the former case subtypes of P2YR, such as P2Y1R and P2Y2R, are G-protein coupled and linked to inositol triphosphate-mediated release of $\mathrm{Ca}^{2+}$ from intracellular endoplasmic reticulum (ER) stores [3-5].

Activation of purinergic receptors alters $\mathrm{Ca}^{2+}$-dependent pathways and intracellular levels of $\mathrm{Ca}^{2+}$ which in turn determine cellular functional responses to endogenous ligand, ATP. For example, ATP stimulation of P2YR not only mobilizes $\left[\mathrm{Ca}^{2+}\right]_{\mathrm{i}}$ from stores but also leads to influx of $\mathrm{Ca}^{2+}$ through store-operated channels (SOC) subsequent to store depletion. An alternative pathway for entry of $\mathrm{Ca}^{2+}$ from extracellular medium is provided by activation of family members of P2XR ionotropic channels. Overall, a diversity of astrocyte functional responses such as cellular growth and proliferation, cytokine production and regulation of cerebral blood flow can depend on the characteristics of $\mathrm{Ca}^{2+}$ signaling in cells $[2,6,7]$.

At present, few studies have addressed the expression and properties of $\mathrm{Ca}^{2+}$ signaling in adult human astrocytes compared with work on rodent astrocytes. Furthermore, the majority of studies on human astrocytes have involved use of fetal cells. Specific properties and activity of astrocytes could differ depending on their species as well as ages. For example, human astrocytes are substantially larger, more complex and propagate $\mathrm{Ca}^{2+}$ signals significantly faster than their rodent counterparts [8]. In humans, adult astrocytes have been reported to proliferate at much lower rate than fetal cells and not to recapitulate the in vitro differentiation [9]. The manner of $\mathrm{Ca}^{2+}$ signaling mediated by purinoceptor activation in adult human astrocytes may have significance in determining astrocyte characteristics, including expression of neurotransmitter receptors, ion channels, transporters and gap junction proteins.

The main purpose of this study was to characterize $\mathrm{Ca}^{2+}$ signaling pathways in adult human astrocytes following activation of purinergic receptors. Calcium-sensitive fluorescence spectroscopy has been used to determine P2YR and P2XR contributions to $\left[\mathrm{Ca}^{2+}\right]_{\mathrm{i}}$ mobilization in stimulated cells. In addition, reverse transcription polymerase chain reaction (RT-PCR) has indicated the expression of
P2Y1R, P2Y2R and P2X7R in the adult human cells. To our knowledge, this work is the first report describing changes in intracellular $\mathrm{Ca}^{2+}$ mobilization associated with activation of purinergic receptors in primary culture of adult human astrocytes.

\section{Methods}

\section{Chemicals and reagents}

ATP, 3'-O-(4-benzoyl)benzoyl-ATP (BzATP), lipopolysaccharide (LPS), gadolinium and dimethyl sulfoxide (DMSO) were obtained from Sigma-Aldrich (St. Louis, MO). ATP and BzATP were dissolved in PBS solution. Fura-2/AM (F-1221) was purchased from Invitrogen Canada (Burlington, ON) and dissolved in DMSO.

\section{Cell culture}

Adult human astrocytes were obtained from epileptic patients undergoing temporal lobe surgery with consents of all patients. Normal brain tissues overlying the epileptic foci were obtained from a standard elective surgical procedure where, in order to remove an epileptic focus, the surgeon first removed normal brain tissue which lies superficial to the previously defined epileptic focus. The epileptic patients were a 27 year-old male, 31 year-old female, 36 year-old female and 41 year-old male. Every brain sample arrived at our laboratory within $24 \mathrm{~h}$ after surgery and was immediately used for astrocyte isolation. The use of human brain materials was approved by the Clinical Research Ethics Board for Human Subjects of the University of British Columbia.

Astrocytes were isolated as described previously [10,11]. They were grown in Dulbecco's modified Eagle mediumnutrient mixture F12 Ham (DMEM-F12) supplemented with $10 \%$ fetal bovine serum and penicillin $(200 \mathrm{U} / \mathrm{ml})$ / streptomycin $(200 \mu \mathrm{g} / \mathrm{ml})$ (all from Invitrogen Canada). Astrocytes were cultured for 3-4 weeks before performing assays. Purity of astrocyte culture was estimated by fluorescent immunocytochemistry with the astrocytic marker glial fibrillar acidic protein (GFAP) (Z334, Dako, Denmark) and counterstaining nuclei with Hoechst 33258 (Hoechst, Frankfurt, Germany). Visualization was achieved using the Alexa Fluor 546 (Invitrogen Canada)-conjugated secondary antibody and a fluorescence microscope (Olympus, BX-51, Tokyo, Japan). Under our culture conditions, more than $99 \%$ cells were positive for GFAP in astrocytic culture.

\section{Calcium spectrofluorometry}

A previous procedure established for measurement of intracellular $\mathrm{Ca}^{2+}$ [12-15] was modified and followed. In brief, $2-5 \times 10^{5}$ of astrocytes plated on 22-mm coverslips (Deckglaser, Sondheim, Germany) were incubated with the fluorescent $\mathrm{Ca}^{2+}$ indicator Fura-2/AM (at $1 \mu \mathrm{M}$ ) plus pluronic acid (at $1 \mu \mathrm{M}$ ) in normal physiological saline 
solution (PSS) for $20 \mathrm{~min}$ at $37^{\circ} \mathrm{C}$. PSS contained (in $\mathrm{mM}$ ): $\mathrm{NaCl}$ (126), $\mathrm{KCl}$ (5), $\mathrm{MgCl}_{2}$ (1.2), HEPES (10), D-glucose (10) and $\mathrm{CaCl}_{2}$ (1); $\mathrm{pH}$ of 7.4. In some experiments, $\mathrm{Ca}^{2+}$-free PSS was used; this solution had the same composition as PSS except that $1 \mathrm{mM}$ of EGTA was added instead of $\mathrm{CaCl}_{2}$. All reagents used in this assay were obtained from Sigma-Aldrich (St. Louis, MO). After a 20-minute wash in dye-free PSS at $37^{\circ} \mathrm{C}$, coverslips were placed on the stage of an inverted microscope equipped with a $40 \times$ objective (Axiovert, Zeiss, Oberkochen, Germany). Cells were exposed to alternating wavelengths of $340 \mathrm{~nm}$ and $380 \mathrm{~nm}$ for excitation at 6-second intervals. Emission light was passed through a 510-nm filter. An imaging system (Empix Imaging, Mississauga, ON, Canada) was used to record fluorescence ratios using a CCD camera (DVC-1310, DVC Company Inc., Austin, TX). The bath chamber was designed to maintain a constant bath volume and standard saline PSS was used to rinse the bath immediately prior to experiments. The bath solution was static with the exception of changes in solution, applied within $60 \mathrm{~s}$ after PSS rinse, and associated with the addition or removal of agonists and antagonists. Responses to purinergic application are presented as fluorescence intensity ratios at excitation wavelengths of 340 to $380 \mathrm{~nm}$ (F340/380) versus time with all experiments performed at room temperature. Amplitudes of all responses in this study are described as ratiometric values derived from the ratio of excitation wavelengths.

ATP-induced responses exhibited fast and slow components of decay. The time course of the rapid initial decay was measured at a point at half-amplitude of peak response. The time course of the secondary slower phase of decay was measured at half-amplitude of this component. The height of the prolonged phase was determined as the point of intersection of the component with time at peak response. ATP response in $\mathrm{Ca}^{2+}$-free PSS or in standard $\mathrm{Ca}^{2+}$ solution containing $\mathrm{Gd}^{3+}$ showed single phase decays from a peak value with time courses determined at half-amplitude values of peak. BzATP-induced response consisted of a single phase of a slowly developing increase to a peak level with amplitude of fluorescent ratio used as a measure of response.

\section{RT-PCR}

Primary human astrocytes were seeded onto 6-well plates $\left(4 \times 10^{5}\right.$ cells per well in $2 \mathrm{ml}$ total volume) in DMEM/ F12 containing 10\% fetal bovine serum. After $48 \mathrm{~h}$, total RNA was isolated using a commercially available kit according to the manufacturer's instructions for adherent

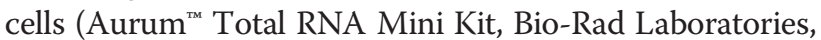
Inc., Hercules, CA). RNA concentration was measured using a spectrophotometer and purity ensured by 260 / $280 \mathrm{~nm}$ ratio of $>1.95$ for all samples. cDNA was reversetranscribed using the qScript ${ }^{\mathrm{m}} \mathrm{cDNA}$ Synthesis Kit from
Quanta Biosciences (Gaithersburg, MD). PCR amplification of cDNA was performed as described previously [16] using GoTaq Green Master Mix (Promega, Madison, WI) on a Bio-Rad C1000 Thermal Cycler. Previously published primer sequences were used: P2Y1 [17]; Forward: 5' GAC TTC TTG TAC GTG CTG ACT CT - 3'; Reverse: 5' - GAC CTC TTG TCA CCT GAT ACG TG - 3'; product size: 647 bp, P2Y2 [18]; Forward: 5' - CTC TAC TTT GTC ACC ACC AG - 3'; Reverse: 5' - TTC TGC TCC TAC AGC CGA AT - 3'; product size: $638 \mathrm{bp}$, and P2X7 [19]; Forward: 5' - TCC GAG AAA CAG GCG ATA A- 3'; Reverse: 5' - ACT CGC ACT TCT TCC TGT A - 3'; product size: 465 bp. PCR conditions consisted of an initial denaturation step at $95^{\circ} \mathrm{C}$ for $2 \mathrm{~min}$, followed by 40 cycles of $30 \mathrm{~s}$ denaturation step at $95^{\circ} \mathrm{C}$, $30 \mathrm{~s}$ annealing step at $53.5^{\circ} \mathrm{C}(\mathrm{P} 2 \mathrm{Y} 1$ and $\mathrm{P} 2 \mathrm{X} 7)$ or $56.5^{\circ} \mathrm{C}$ (P2Y2), and $1 \mathrm{~min}$ extension step at $72^{\circ} \mathrm{C}$. A final extension step of $5 \mathrm{~min}$ at $72^{\circ} \mathrm{C}$ was also performed. PCR products were separated by electrophoresis on a $1 \%$ agarose gel and visualized with SYBR safe DNA gel stain (Invitrogen, Eugene, OR). Digital photographs of the gels were taken with the Fluorchem FC2 imaging and image analysis system from Alpha Innotech (Santa Clara, CA). All PCR results were derived with cycle number producing a signal in the linear portion of the amplification curve.

\section{Statistics}

Data are presented as means \pm standard error of mean (SEM). Statistical significance was determined using oneway analysis of variance (ANOVA) followed by StudentNewman-Keuls multiple comparison test. $\mathrm{P}<0.05$ was considered statistically significant.

\section{Results}

\section{ATP-induced changes in $\left[\mathrm{Ca}^{2+}\right]_{\mathrm{i}}$}

We first confirmed that in excess of $99 \%$ cells in astrocyte culture were positive for GFAP under our culture conditions (see Methods). A representative image of cultured cells is presented in Figure 1.

Calcium-dependent spectrofluorescence was used to examine effects of ATP on $\left[\mathrm{Ca}^{2+}\right]_{\mathrm{i}}$ in adult human astrocytes. The experiments generally employed $1 \mathrm{mM}$ of ATP (application time of $200 \mathrm{~s}$ ); this level of ATP is insufficient to activate the P2X7 subtype ionotropic receptor in human microglia [4]. We initially measured the effect of ATP on intracellular calcium mobilization in standard PSS with the change in $\left[\mathrm{Ca}^{2+}\right]_{i}$ exhibiting a biphasic time course (Figure $2 \mathrm{~A})$. Overall $(\mathrm{N}=4$ experiments, total of 76 cells), respective time courses for ATP applied in PSS were $19.1 \pm 0.8 \mathrm{~s}$ and $55.9 \pm 3.6 \mathrm{~s}$ for the fast and slow phases of $\left[\mathrm{Ca}^{2+}\right]_{\mathrm{i}}$. We also examined, in a single experiment, for effects of a 10-fold lower concentration of ATP (at $100 \mu \mathrm{M}$ ). As shown in Figure 2B, the 


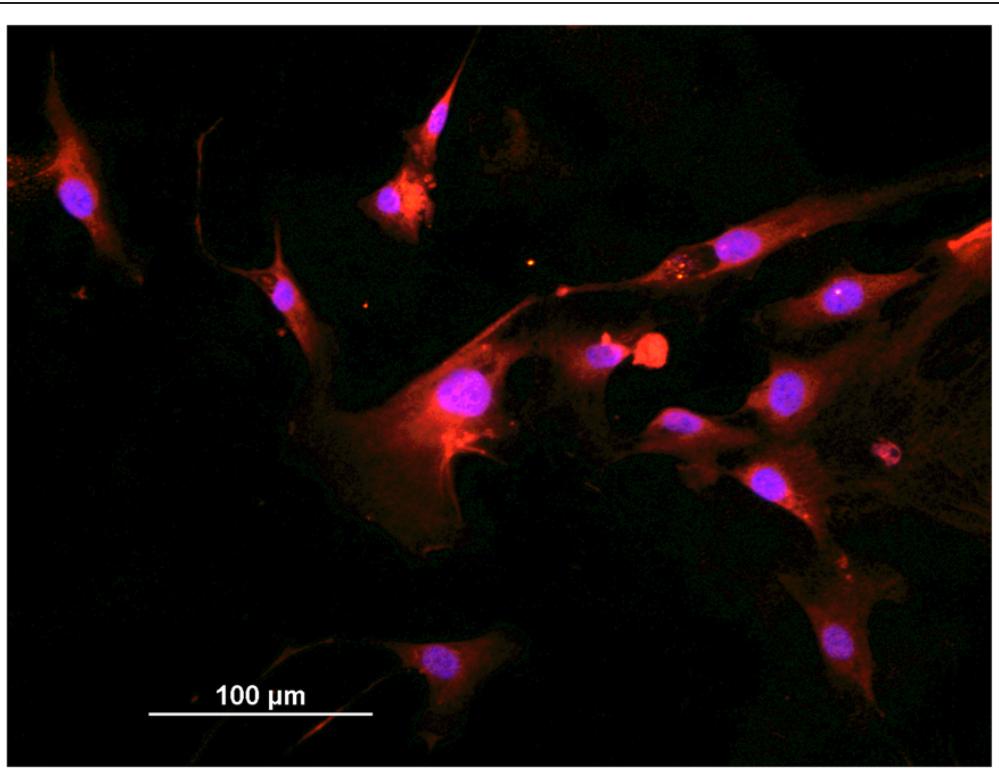

Figure 1 Immunocytochemistry of cultured adult human astrocytes. Representative image of purified culture of adult human astrocytes stained with GFAP (red). Cellular nuclei were counterstained with Hoechst 33258 (blue).

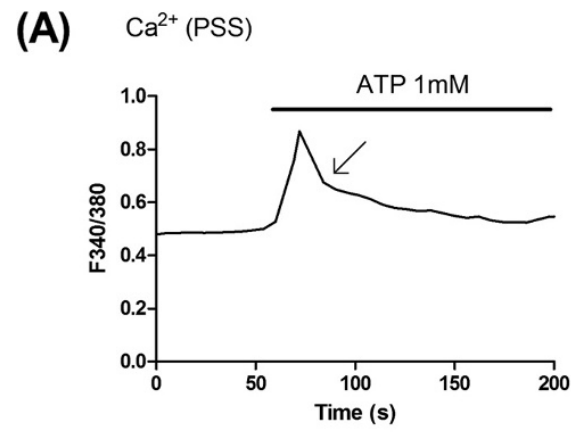

(C)

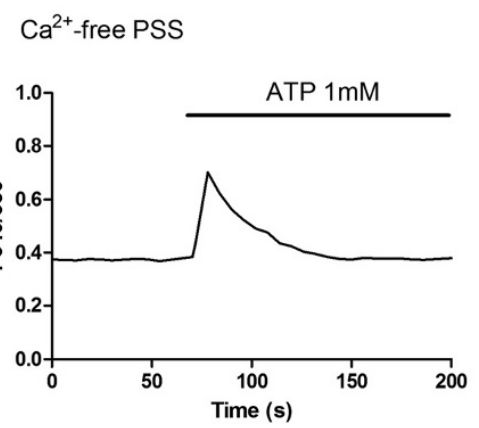

(B)

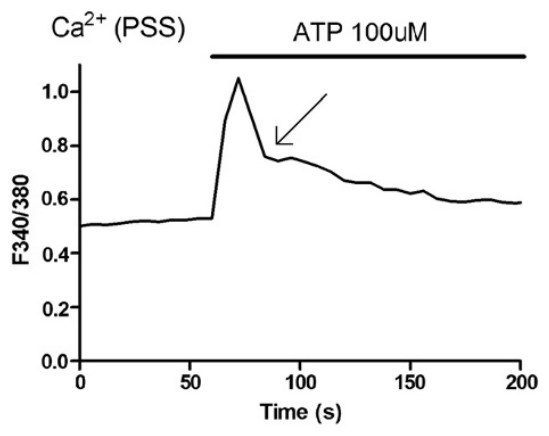

(D)

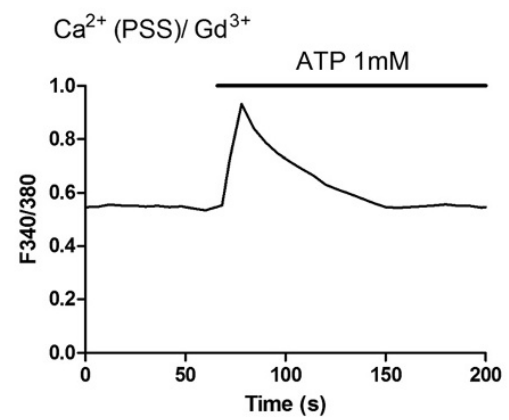

Figure 2 Intracellular calcium responses to ATP in adult human astrocytes. (A) Representative change in intracellular $\mathrm{Ca}^{2+}\left(\left[\mathrm{Ca}^{2+}\right]_{i}\right)$ (response collated from 20 cells) to ATP (applied at $1 \mathrm{mM}$ ) in $\mathrm{Ca}^{2+}$-containing physiological saline solution (PSS). The change in $\left[\mathrm{Ca}^{2+}\right]_{i}$ exhibited a biphasic time course with time components of $18.5 \mathrm{~s}$ and $49 \mathrm{~s}$ for the fast and slow phases of decay, respectively. The arrow indicates the inflection point between the rapid and prolonged components of the decay phase of response. (B) Typical mobilization of $\left[\mathrm{Ca}^{2+}\right]_{\mathrm{i}}(\mathrm{response}$ collated from 9 cells) induced by a lower level of ATP (applied at $100 \mu \mathrm{M}$ ) in standard PSS. A biphasic change in $\left[\mathrm{Ca}^{2+}\right]_{\mathrm{i}}$ was observed (arrow indicated inflection point) with respective rapid and slow component decay times of $17.8 \mathrm{~s}$ and $58.7 \mathrm{~s}$. (C) Representative $\left[\mathrm{Ca}^{2+}\right]_{i}$ mobilization (response collated from 22 cells) to $1 \mathrm{mM}$ ATP applied in $\mathrm{Ca}^{2+}$-free PSS. A single component of decay of response was observed with a time course of $23.2 \mathrm{~s}$. (D) Representative change in $\left[\mathrm{Ca}^{2+}\right]_{\mathrm{i}}$ (response collated from 20 cells) to $1 \mathrm{mM}$ ATP in the presence of gadolinium (Gd ${ }^{3+}$ at $2 \mu \mathrm{M}$ pretreatment for $200 \mathrm{~s}$ ) in standard PSS. A single monophasic time course of decay for $\left[\mathrm{Ca}^{2+}\right]_{i}$ was observed with a time course of $25.6 \mathrm{~s}$. All cells shown in this figure were obtained and cultured from a single human surgical case. 
response to $100 \mu \mathrm{M}$ ATP showed a similar biphasic time course as found with the higher ATP concentration (Figure 2A). The results from control experiments are consistent with the possibility that $\mathrm{Ca}^{2+}$ responses, induced by different concentrations of ATP in standard PSS, are mediated by a rapid release of intracellular $\mathrm{Ca}^{2+}$ followed by a secondary component of influx.

Physiological and pharmacological protocols were used to examine modulation of $\mathrm{Ca}^{2+}$ entry into adult human astrocytes using application of $1 \mathrm{mM}$ ATP. In one set of experiments, extracellular $\mathrm{Ca}^{2+}$ was replaced with $\mathrm{Ca}^{2+}$-free PSS to prevent influx of $\mathrm{Ca}^{2+}$ as a contributing mechanism for changes in $\left[\mathrm{Ca}^{2+}\right]_{\mathrm{i}}$. A typical astrocytic response induced by ATP in $\mathrm{Ca}^{2+}$-free PSS is presented in Figure $2 \mathrm{C}$. It showed a single declining phase with no prolonged component of decay. The absence of the delayed phase of $\left[\mathrm{Ca}^{2+}\right]_{i}$ in $\mathrm{Ca}^{2+}$-free solution is consistent with influx of extracellular $\mathrm{Ca}^{2+}$ mediating this component of response. In three additional experiments, the secondary slow phase of response was absent in $\mathrm{Ca}^{2+}$-free solution. Overall results $(\mathrm{N}=4$ experiments, total of 85 cells $)$ yielded a single time course of decay in $\mathrm{Ca}^{2+}$-free PSS was $28.9 \pm 1.8 \mathrm{~s}$. This decay time course was not significantly different $(p>0.05)$ from the rapid time course of the control response evoked by $1 \mathrm{mM}$ ATP (Figure 2A).

The prolonged phase of $\left[\mathrm{Ca}^{2+}\right]_{\mathrm{i}}$ elicited by ATP in standard PSS (Figure 2A, B) and its absence in $\mathrm{Ca}^{2+}$-free PSS (Figure 2C) could reflect entry of $\mathrm{Ca}^{2+}$ through SOC following the initial release of the divalent ion from internal stores. To investigate this possibility, ATPinduced responses were studied with $2 \mu \mathrm{M}$ of gadolinium $\left(\mathrm{Gd}^{3+}\right)$ added to standard PSS. Inhibition of SOC with $\mathrm{Gd}^{3+}$ has previously been demonstrated in a variety of cell types, including smooth muscle and glioma cells $[14,20]$. A representative response is shown in Figure 2D for the $\left[\mathrm{Ca}^{2+}\right]_{\mathrm{i}}$ change induced by $1 \mathrm{mM}$ ATP in human astrocytes exposed to $\mathrm{Gd}^{3+}$. A single monophasic time course of decay for $\left[\mathrm{Ca}^{2+}\right]_{i}$ was observed, indicating that addition of $\mathrm{Gd}^{3+}$ to standard PSS inhibits the prolonged component of the ATP response. Overall $(\mathrm{N}=4$ experiments, total of 79 cells), ATP induced a single time course of decay with mean value of $29.3 \pm 5.2 \mathrm{~s}$ when $\mathrm{Gd}^{3+}$ was added to PSS. This time course of response was not significantly different $(\mathrm{p}>0.05)$ from the rapid phase of decay in control induced by $1 \mathrm{mM}$ ATP (Figure 2A).

\section{BzATP-induced changes in $\left[\mathrm{Ca}^{2+}\right]_{i}$}

Figure 3A represents a typical intracellular $\mathrm{Ca}^{2+}$ response evoked by BzATP (at $300 \mu \mathrm{M}$ ). The response was considerably different from that induced by ATP (Figure 2A, B) and was characterized by a slow progressive increase in $\left[\mathrm{Ca}^{2+}\right]_{\mathrm{i}}$ to a peak level; experiments were terminated at 10 min after BzATP application. Similar results were found in 3 additional experiments whereby responses

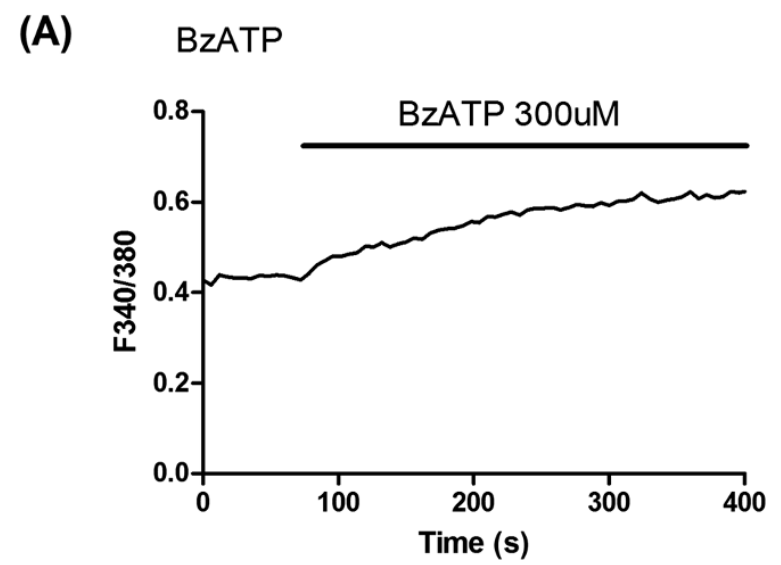

(B)

\section{BzATP/LPS pretx}

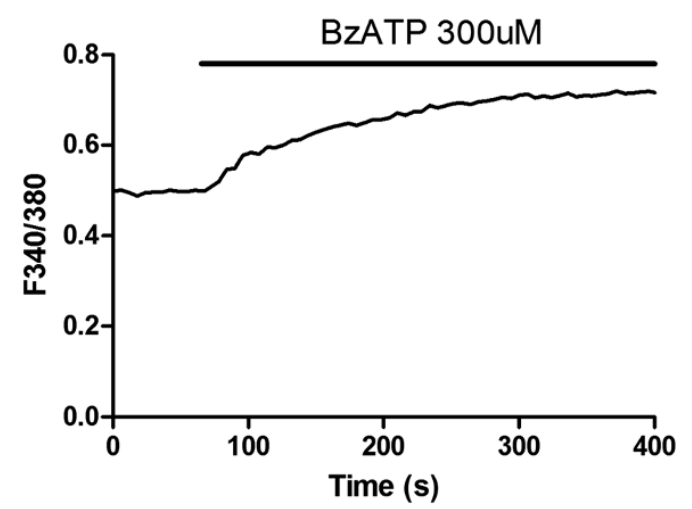

Figure 3 Intracellular calcium responses to BzATP in adult human astrocytes. (A) Representative change in intracellular $\mathrm{Ca}^{2+}$ $\left(\left[\mathrm{Ca}^{2+}\right]_{i}\right)$ (response collated from 21 cells) to BzATP (applied at $\left.300 \mu \mathrm{M}\right)$. The amplitude of response, expressed as a ratio of fluorescent intensity 340/380, was 0.23. (B) Representative change in $\left[\mathrm{Ca}^{2+}\right]_{\mathrm{i}}$ (response collated from 25 cells) to BzATP in the presence of lipopolysaccharide (LPS at $100 \mathrm{ng} / \mathrm{ml}$, pretreatment for $16 \mathrm{~h}$ ). The amplitude of response (F340/380) was 0.26 from baseline to plateau level. Data shown in this figure was recorded from cells obtained and cultured from one surgical case.

were characterized by a slow increase of $\left[\mathrm{Ca}^{2+}\right]_{\mathrm{i}}$ over a 10 min application of BzATP. Overall $(\mathrm{N}=4$ experiments, total of 57 cells), the mean amplitude of $\left[\mathrm{Ca}^{2+}\right]_{\mathrm{i}}$ was $0.21 \pm 0.02$ in control.

Previous work has demonstrated LPS priming of BzATP responses, measured as amplitudes of fluorescent ratio, in microglia which was attributed to inflammatory enhancement in numbers of P2X7R [13]. This finding prompted us to examine LPS as a modulatory agent for purinergic response in adult human astrocytes. LPS pretreatment (100 $\mathrm{ng} / \mathrm{ml}$ for $16 \mathrm{~h}$ ) was used as an inflammatory stimulus for adult human astrocytes. Figure $3 \mathrm{~B}$ shows a representative change in $\left[\mathrm{Ca}^{2+}\right]_{\mathrm{i}}$ induced by BzATP for cells administered LPS treatment. Overall $(\mathrm{N}=4$ experiments, total of 49 cells), the amplitude of the BzATP-induced response was $0.24 \pm 0.03$ with LPS treatment compared with 
an amplitude of $0.21 \pm 0.02$ in the absence of LPS treatment. This difference was not significant $(p>0.05)$ indicating LPS was ineffective as a modulatory stimulus to enhance purinergic responses to BzATP in adult human astrocytes.

\section{Expression of P2Y1R, P2Y2R and P2X7R in adult human astrocytes}

The results from imaging experiments for changes in $\left[\mathrm{Ca}^{2+}\right]_{\mathrm{i}}$ suggest functional expression of metabotropic and ionotropic P2R subtypes in cultured adult human astrocytes. We therefore carried out RT-PCR to examine expression for particular P2R, including P2Y1R, P2Y2R and P2X7R, which have previously been reported to mediate $\mathrm{Ca}^{2+}$ response $[4,21]$. Figure 4 shows the astrocytic expression of mRNA encoding P2Y1R, P2Y2R and P2X7R. The mRNA expression of all these subtypes was detected in 3 different individuals.

\section{Discussion}

To our knowledge, this is the first study that demonstrates intracellular $\mathrm{Ca}^{2+}$ mobilization following activation of purinergic receptors in cultures of primary adult human astrocytes. We report ATP induction of intracellular $\mathrm{Ca}^{2+}$ mobilization mediated by depletion of intracellular stores consistent with activation of metabotropic P2YR in adult human astrocytes. This component of $\left[\mathrm{Ca}^{2+}\right]_{\mathrm{i}}$ change is followed by a subsequent influx of $\mathrm{Ca}^{2+}$ through SOC. RT-PCR analysis demonstrated the expression of specific subtype metabotropic P2Y1R and P2Y2R in addition to ionotropic P2X7R. Interestingly, this expression pattern of P2 purinoceptor in adult human astrocytes is consistent with observations made in fetal human [17] and newborn rat [22] astrocytes.

ATP stimulation of adult human astrocytes mobilized intracellular $\mathrm{Ca}^{2+}$ with a response characterized by two components of decay. The initial rapid transient component following peak response is consistent with activation of metabotropic P2YR and mediated by $\mathrm{Ca}^{2+}$ release from ER stores independent of extracellular $\mathrm{Ca}^{2+}[4,14]$. The subsequent prolonged component was considerably attenuated with ATP application in $\mathrm{Ca}^{2+}$-free PSS, indicating this phase of response was due to $\mathrm{Ca}^{2+}$ influx through plasmalemmal membrane [4]. This secondary component of response likely represents $\mathrm{Ca}^{2+}$ entry through SOC since the component was inhibited in the presence of the SOC antagonist, $\mathrm{Gd}^{3+}[14,20]$. The single time courses of $\left[\mathrm{Ca}^{2+}\right]_{\mathrm{i}}$ elicited by ATP in $\mathrm{Ca}^{2+}$-free and in $\mathrm{Gd}^{3+}$ with standard $\mathrm{Ca}^{2+}$ PSS (200 s treatment) were similar in magnitude (near $29 \mathrm{~s}$ ) and somewhat longer than the rapid phase evoked by ATP in standard $\mathrm{Ca}^{2+}$ solution. This result suggests that only a partial inhibition of SOC was attained with astrocytes exposed to $2 \mu \mathrm{M} \mathrm{Gd}{ }^{3+}$ for a duration $200 \mathrm{~s}$. A possible explanation for the longer time

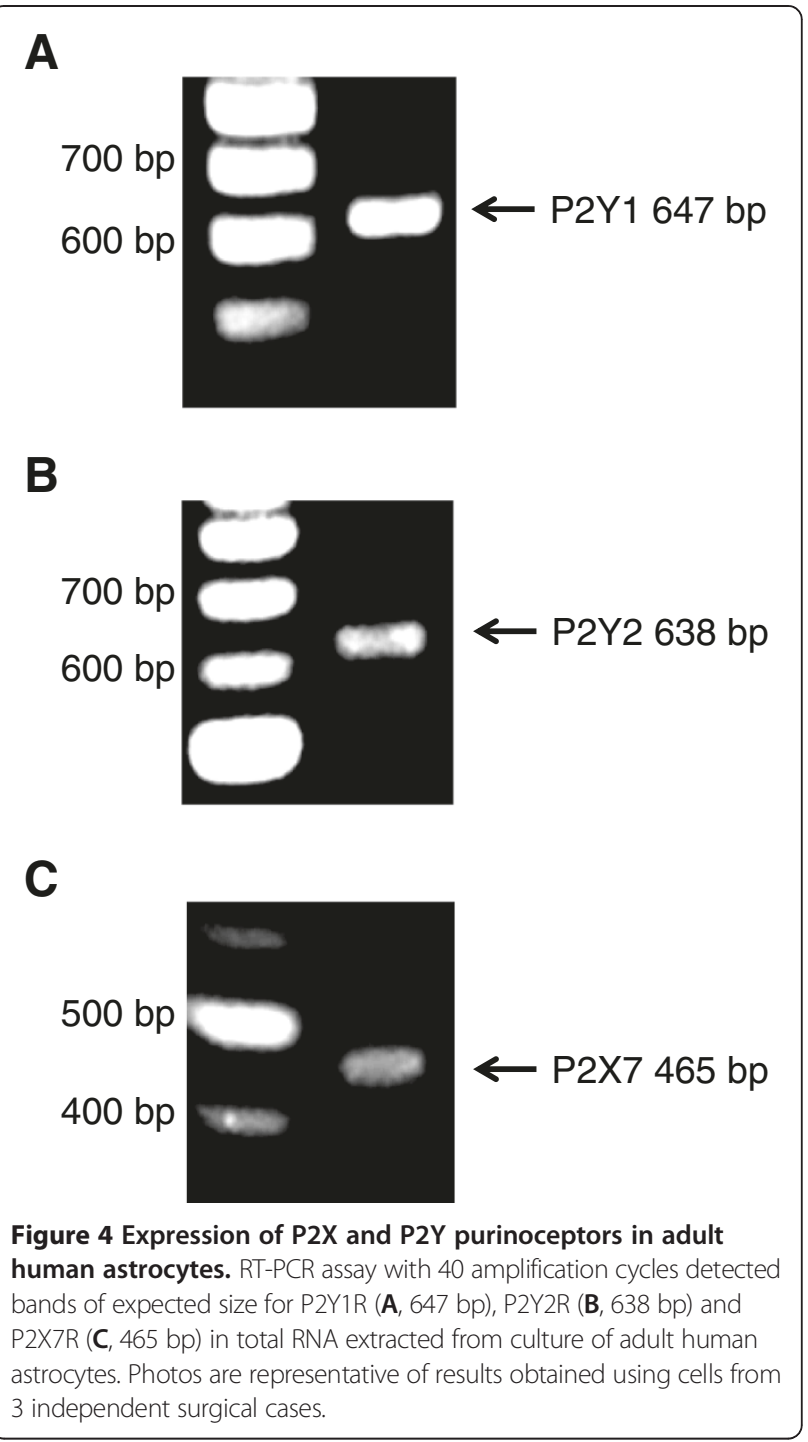

course of decay in $\mathrm{Ca}^{2+}$-free PSS, relative to the rapid phase of control ATP response in PSS, is that residual $\mathrm{Ca}^{2+}$ could remain in nominally $\mathrm{Ca}^{2+}$-free solution. In order to minimize effects of non-physiological $\mathrm{Ca}^{2+}$-free PSS on cell viability, we employed relatively short treatment times of $60 \mathrm{~s}$ with this solution prior to ATP stimulation. We did not test $\mathrm{Gd}^{3+}$ at concentrations higher than $2 \mu \mathrm{M}$ nor increase incubation time with $\mathrm{Ca}^{2+}$-free PSS to detect astrocytic responses in a robust and healthy condition. The overall results from calcium imaging experiments suggest that purinergic response to endogenous ligand in adult human astrocytes is mediated by ATP binding to metabotropic P2YR with subsequent mobilization of $\left[\mathrm{Ca}^{2+}\right]_{\mathrm{i}}$ due to intracellular release and influx through SOC.

$\mathrm{Ca}^{2+}$ spectrofluorometry showed that application of BzATP elicited a gradual and sustained increase in $\left[\mathrm{Ca}^{2+}\right]_{\mathrm{i}}$ in adult human astrocytes. This finding suggests influx of 
$\mathrm{Ca}^{2+}$ through the nonselective cationic channel coupled to activation of P2X7R [1,4] and is consistent with previous work demonstrating a modest and prolonged $\left[\mathrm{Ca}^{2+}\right]_{i}$ rise elicited by BzATP in fetal human astrocytes [21].

Purinergic agonists and antagonists are notorious for non-specific activity [23,24]. Although BzATP has been reported as an activator of P2X7R in numerous studies $[12,13,15,25]$, considerable non-specificity of the ligand has also been documented. Examples include actions of BzATP mediated by ionotropic P2X1 and P2X3 [26] and metabotropic P2Y2 [27] receptors. Recent work on rodent cerebellar astrocytes has demonstrated calcium responses mediated by P2Y13 receptors in addition to P2X7R activation [28]. In addition, BzATP responses have been attributed to activation of adenosine receptors, an effect involving dephosphorylation activity of ecto-nucleotidases [29]. It should also be noted that interpretation of BzATPinduced responses is further complicated by the variability in actions of P2X7R antagonists with Brilliant blue G [30] exhibiting a greater selectivity for P2X7R inhibitory activity compared with oxidized ATP [31]. Overall, a multiplicity of purinergic receptors could contribute to BzATP responses in addition to the activation of P2X7R.

We found that LPS priming of human astrocytes $(100 \mathrm{ng} / \mathrm{ml}$ for $16 \mathrm{~h})$ had no significant effect to alter amplitude of BzATP-induced responses compared with controls (no LPS pretreatment). Interestingly, this result is in contrast to previous findings on fetal human microglia which demonstrated that exposure of cells to LPS (100 $\mathrm{ng} / \mathrm{ml}$ for $2 \mathrm{~h}$ ) significantly enhanced the amplitude of BzATP-evoked $\left[\mathrm{Ca}^{2+}\right]_{i}[13]$. One possibility for the differences of LPS treatment on $\mathrm{Ca}^{2+}$ mobilization in astrocytes and microglia may be related to differential cellular expression of receptors for LPS. In particular CD14, a putative LPS receptor, is not expressed in human astrocytes [32] whereas this receptor is expressed in human microglia, the resident immune responding cells in brain [33].

\section{Conclusions}

Our study has presented novel findings concerning expression and activation of specific purinergic $\mathrm{Ca}^{2+}$ signaling pathways in cultured adult human astrocytes. Metabotropic P2YR and ionotropic P2XR are putative mediators of purinergic responses in the cells. Future studies using adult human astrocytes are warranted to characterize the specific roles of the purinergic receptors in mediating cellular responses. Such work will enable clarification of downstream $\mathrm{Ca}^{2+}$-dependent and independent signaling pathways. P2X7R expression and function should be confirmed in these cells followed by examination of roles of the receptor in mediating astrocytic responses in pathological microenvironments in human brain.

\section{Competing interests}

The authors declare that they have no competing interests.

\section{Authors' contributions}

SH, YFW and JGM participated in the design of the study. SH and YFW carried out all experiments, collected the data and performed the statistical analysis. JPL and AK performed the RT-PCR analysis. HCB participated in calcium spectrofluorometry. SH, YFW and JGM interpreted the data. SH and JGM wrote the manuscript. JGM, HCB, AK and PLM revised the manuscript. All authors read and approved the final manuscript.

\section{Acknowledgments}

This research was supported by the Pacific Alzheimer Research Foundation (SH, PLM and JGM), Grant-in-Aid for Scientific Research \#24591721 (SH) and the Jack Brown and Family Alzheimer's Disease Research Foundation (JPL and AK).

\section{Author details}

${ }^{1}$ Kinsmen Laboratory of Neurological Research, Department of Psychiatry, The University of British Columbia, Vancouver, BC, Canada. ${ }^{2}$ Department of Anesthesiology, Pharmacology and Therapeutics, The University of British Columbia, 2176 Health Sciences Mall, Vancouver, BC V6T 1Z3, Canada. ${ }^{3}$ Department of Biology, I.K. Barber School of Arts and Sciences, The University of British Columbia Okanagan Campus, Kelowna, BC, Canada. ${ }^{4}$ Present affiliation; Department of Psychiatry, Faculty of Medicine, Shimane University, 89-1 Enya-cho, Izumo, Shimane 693-8501, Japan.

Received: 5 July 2013 Accepted: 15 January 2014

Published: 22 January 2014

\section{References}

1. Butt AM: ATP: a ubiquitous gliotransmitter integrating neuron-glial networks. Semin Cell Dev Biol 2011, 22:205-213.

2. James G, Butt AM: $P 2 Y$ and $P 2 X$ purinoceptor mediated $C a 2+$ signalling in glial cell pathology in the central nervous system. Eur J Pharmacol 2002, 447:247-260.

3. Abbracchio MP, Burnstock G, Boeynaems JM, Barnard EA, Boyer JL, Kennedy C, Knight GE, Fumagalli M, Gachet C, Jacobson KA, Weisman GA: International Union of Pharmacology LVIII: update on the P2Y G protein-coupled nucleotide receptors: from molecular mechanisms and pathophysiology to therapy. Pharmacol Rev 2006, 58:281-341.

4. McLarnon JG: Purinergic mediated changes in Ca2+ mobilization and functional responses in microglia: effects of low levels of ATP. J Neurosci Res 2005, 81:349-356.

5. Neary JT, Zimmermann H: Trophic functions of nucleotides in the central nervous system. Trends Neurosci 2009, 32:189-198.

6. Mulligan SJ, MacVicar BA: Calcium transients in astrocyte endfeet cause cerebrovascular constrictions. Nature 2004, 431:195-199.

7. Straub SV, Nelson MT: Astrocytic calcium signaling: the information currency coupling neuronal activity to the cerebral microcirculation. Trends Cardiovasc Med 2007, 17:183-190.

8. Oberheim NA, Goldman SA, Nedergaard M: Heterogeneity of astrocytic form and function. Methods Mol Biol 2012, 814:23-45.

9. Sharif A, Prevot V: Isolation and culture of human astrocytes. Methods $\mathrm{Mol}$ Biol 2012, 814:137-151.

10. Hashioka S, Klegeris A, Schwab C, McGeer PL: Interferon-gammadependent cytotoxic activation of human astrocytes and astrocytoma cells. Neurobiol Aging 2009, 30:1924-1935.

11. Hashioka S, Klegeris A, Qing H, McGeer PL: STAT3 inhibitors attenuate interferon-gamma-induced neurotoxicity and inflammatory molecule production by human astrocytes. Neurobiol Dis 2011, 41:299-307.

12. Choi HB, Hong SH, Ryu JK, Kim SU, McLarnon JG: Differential activation of subtype purinergic receptors modulates $\mathrm{Ca}(2+)$ mobilization and $\mathrm{COX}-2$ in human microglia. Glia 2003, 43:95-103.

13. Choi HB, Ryu JK, Kim SU, McLarnon JG: Modulation of the purinergic P2X7 receptor attenuates lipopolysaccharide-mediated microglial activation and neuronal damage in inflamed brain. J Neurosci 2007, 27:4957-4968.

14. Jantaratnotai N, Choi HB, McLarnon JG: ATP stimulates chemokine production via a store-operated calcium entry pathway in C6 glioma cells. BMC Cancer 2009, 9:442. 
15. McLarnon JG, Ryu JK, Walker DG, Choi HB: Upregulated expression of purinergic P2X(7) receptor in Alzheimer disease and amyloid-beta peptide-treated microglia and in peptide-injected rat hippocampus. J Neuropathol Exp Neurol 2006, 65:1090-1097.

16. Villanueva EB, Little JP, Lambeau G, Klegeris A: Secreted phospholipase A (2) group IIA is a neurotoxin released by stimulated human glial cells. Mol Cell Neurosci 2012, 49:430-438.

17. John GR, Simpson JE, Woodroofe MN, Lee SC, Brosnan CF: Extracellular nucleotides differentially regulate interleukin- 1 beta signaling in primary human astrocytes: implications for inflammatory gene expression. J Neurosci 2001, 21:4134-4142.

18. Adrian $\mathrm{K}$, Bernhard MK, Breitinger HG, Ogilvie A: Expression of purinergic receptors (ionotropic P2X1-7 and metabotropic P2Y1-11) during myeloid differentiation of HL60 cells. Biochim Biophys Acta 2000, 1492:127-138.

19. Budagian V, Bulanova E, Brovko L, Orinska Z, Fayad R, Paus R, Bulfone-Paus S: Signaling through P2X7 receptor in human T cells involves p56lck, MAP kinases, and transcription factors AP-1 and NF-kappa B. J Biol Chem 2003, 278:1549-1560.

20. Flemming R, Xu SZ, Beech DJ: Pharmacological profile of store-operated channels in cerebral arteriolar smooth muscle cells. Br J Pharmacol 2003, 139:955-965.

21. Narcisse L, Scemes E, Zhao Y, Lee SC, Brosnan CF: The cytokine IL-1 beta transiently enhances $\mathrm{P} 2 \mathrm{X} 7$ receptor expression and function in human astrocytes. Glia 2005, 49:245-258.

22. Jimenez Al, Castro E, Communi D, Boeynaems JM, Delicado EG, MirasPortugal MT: Coexpression of several types of metabotropic nucleotide receptors in single cerebellar astrocytes. J Neurochem 2000, 75:2071-2079.

23. Anderson $C M$, Nedergaard $M$ : Emerging challenges of assigning P2X7 receptor function and immunoreactivity in neurons. Trends Neurosci 2006, 29:257-262.

24. North RA: Molecular physiology of P2X receptors. Physiol Rev 2002, 82:1013-1067.

25. Ryu JK, Jantaratnotai N, Serrano-Perez MC, McGeer PL, McLarnon JG: Block of purinergic P2X7R inhibits tumor growth in a C6 glioma brain tumor animal model. J Neuropathol Exp Neurol 2011, 70:13-22.

26. Bianchi BR, Lynch KJ, Touma E, Niforatos W, Burgard EC, Alexander KM, Park HS, Yu H, Metzger R, Kowaluk E, et al: Pharmacological characterization of recombinant human and rat P2X receptor subtypes. Eur J Pharmacol 1999, 376:127-138.

27. Fedorov IV, Rogachevskaja OA, Kolesnikov SS: Modeling P2Y receptor-Ca2+ response coupling in taste cells. Biochim Biophys Acta 2007, 1768:1727-1740

28. Carrasquero LM, Delicado EG, Bustillo D, Gutierrez-Martin Y, Artalejo AR, Miras-Portugal MT: P2X7 and P2Y13 purinergic receptors mediate intracellular calcium responses to BzATP in rat cerebellar astrocytes. J Neurochem 2009, 110:879-889.

29. Kukley M, Stausberg P, Adelmann G, Chessell IP, Dietrich D: Ecto-nucleotidases and nucleoside transporters mediate activation of adenosine receptors on hippocampal mossy fibers by $\mathrm{P} 2 \mathrm{X} 7$ receptor agonist 2'-3'-O(4-benzoylbenzoyl)-ATP. J Neurosci 2004, 24:7128-7139.

30. Jiang $L H$, Mackenzie $A B$, North RA, Surprenant A: Brilliant blue $G$ selectively blocks ATP-gated rat P2X(7) receptors. Mol Pharmacol 2000, 58:82-88.

31. Evans RJ, Lewis C, Buell G, Valera S, North RA, Surprenant A: Pharmacological characterization of heterologously expressed ATP-gated cation channels (P2x purinoceptors). Mol Pharmacol 1995, 48:178-183.

32. Farina C, Aloisi F, Meinl E: Astrocytes are active players in cerebral innate immunity. Trends Immunol 2007, 28:138-145.

33. Lambert C, Desbarats J, Arbour N, Hall JA, Olivier A, Bar-Or A, Antel JP: Dendritic cell differentiation signals induce anti-inflammatory properties in human adult microglia. J Immunol 2008, 181:8288-8297.

doi:10.1186/1471-2202-15-18

Cite this article as: Hashioka et al:: Purinergic responses of calciumdependent signaling pathways in cultured adult human astrocytes. $B M C$ Neuroscience 2014 15:18.

\section{Submit your next manuscript to BioMed Central and take full advantage of:}

- Convenient online submission

- Thorough peer review

- No space constraints or color figure charges

- Immediate publication on acceptance

- Inclusion in PubMed, CAS, Scopus and Google Scholar

- Research which is freely available for redistribution

Submit your manuscript at www.biomedcentral.com/submit
Biomed Central 